DOI: https://doi.org/10.11144/Javeriana.upsy18-1.ccpp

\title{
La comunicación científica y la política pública: ¿Es posible una política pública basada en la evidencia?
}

WiLSON López López

Pontificia Universidad Javeriana, Colombia

ORCID: http://orcid.org/0000-0002-2964-0402

Para citar esta editorial: López López, W. (2019). La comunicación científica y la política pública: ¿Es posible una política pública basada en la evidencia? [Editorial]. Universitas Psychologica, 18(1), 1-3. https://doi.org/10.11144/Javeriana.upsy18-1.ccpp
Las publicaciones científicas buscan no solo ser canales de diálogo y confianza en las comunidades académicas, sino también que sus productos incidan en las sociedades. La credibilidad de este ciclo descansa en que los procesos de revisión por pares garanticen la calidad de los artefactos derivados de la investigación (López-López et al., 2018).

En este mismo sentido, el conocimiento que se visibiliza en las publicaciones académicas nutre el desarrollo de procesos de innovación cuando va a las patentes, y estas generan transformaciones diversas en el mundo productivo o del bienestar humano. No obstante, no todos los procesos de innovación pasan por este circuito de investigación científica como base del desarrollo tecnológico, en ocasiones, estos desarrollos transitan por rutas más azarosas sujetas a externalidades que suelen acelerar los procesos de producción de cambio tecnológico. A pesar de las diferencias en los procesos de estos dos tipos de conocimiento, científico y tecnológico, ambos comparten numerosos procedimientos de validación, antes de asumir el escenario público o formar parte de los sistemas de regulación social (Bunge, 1999, 2003; Quintanilla, 2012).

Los universos disciplinares, por otro lado, tienen dinámicas donde se diferencian las relaciones entre ciencia, tecnología y sociedad, pues parece evidente que no son iguales entre la física y las ingenierías, o entre la biología y la medicina, o entre la sociología y la ciencia política; incluso, tenemos algunas disciplinas que se mueven con dinámicas en las que los productos de conocimiento buscan desarrollar tecnologías y, al mismo tiempo, resolver problemas fundamentales. En algunas de ellas, se confunden los procesos, distanciándose hasta el punto de romper los vínculos a su interior, sin embargo, estos hacen emerger nuevas áreas e incluso generan nuevos artefactos que no siempre pasan por la revisión y la 
evaluación necesaria, para ser transformados en un producto de incidencia social (Bunge, 2003; Olive, 2013).

Los productos derivados de las disciplinas que se encuentran en el escenario de las ciencias sociales tienen diversos caminos; así, es frecuente observar como la sociología, la ciencia política, la antropología y la economía son usualmente utilizadas como recursos para aportar a la sociedad, y los políticos las emplean como recursos de toma de decisiones de legitimación de sus acciones o incluso de producción de política pública. En este sentido, una parte del trabajo de los científicos termina en artefactos o innovaciones sociales, aunque es importante reconocer que con frecuencia estas son vulnerables a las presiones de actores, decisores de escenarios económicos o políticos, y su trabajo termina por incidir incluso en los diseños que adquiere la sociedad. Un ejemplo de esto fueron las decisiones de política económica que deprimieron la inversión pública, después de las recesiones que habían sido previstas por los modelos de predicción de académicos, y que luego mostraron ser caminos equivocados de los cuales se beneficiaron algunos actores. Es necesario señalar que estas no suelen ser prácticas generalizadas, pero que sí muestran una vulnerabilidad a la que se dirige la investigación científica, el desarrollo tecnológico y la aplicación social.

Para la psicología, esta relación se complejiza en diversas formas; de un lado, por sus múltiples relaciones con las ciencias de la salud, con ciencias sociales como la economía, la sociología, las ciencias políticas y de la comunicación, y con disciplinas emergentes como la neurociencia. Por otro lado, la ciencia psicológica no siempre ha articulado el camino de los desarrollos en psicología básica y aplicada con las innovaciones desde el mundo profesional; estas diferencias se expresan en las disputas de las comunidades de la psicología organizada. Un ejemplo de esto suelen ser los conflictos entre colegios u organizaciones profesionales y sociedades académicas como las universidades, lo que inevitablemente repercute en las dinámicas de formación, producción y comunicación científica de la disciplina (LópezLópez et al., 2018).

Evidentemente, los métodos de regulación y de aseguramiento de la calidad de la producción de conocimiento en el mundo académico, tienen múltiples actores y sistemas de control para asegurar su calidad, y no siempre el mundo profesional cuenta con los mismos procesos de regulación, lo cual ocasiona problemas de credibilidad en la opinión pública (Mitcham \& Mackey, 2004; Olive, 2013; Quintanilla, 2012). Por tanto, las comunidades organizadas deben garantizar que la producción de artefactos cognitivos y los desarrollos psicotecnológicos cuenten con procesos de evaluación que aseguren la calidad de la evidencia producida, de forma que estos puedan ser usados como recursos de incidencia social o de política pública por las comunidades o los actores decisores. En esta dirección, la psicología organizada seguramente deberá emprender acciones de comunicación a la sociedad, que permitan influir en ella con el conocimiento fundamentado en la evidencia y desarrollado por nuestra disciplina, aportando a la toma de decisiones que impacten en la misma, sin irrumpir su tejido y mitigando los daños. De esta manera, jugarían un papel transformador para mejorar el bienestar humano o, como mínimo, permitirían la denuncia de decisiones que afecten a la sociedad.

\section{Referencias}

Bunge, M. (1999). Las ciencias sociales en discusión. Buenos Aires: Suramericana.

Bunge, M. (2003). Emergencia y convergencia. Barcelona: Gedisa.

López-López, W., Caycedo, C., Acevedo Triana, C., Hurtado-Parrado, C., Silva, L., \& Aguilar-Bustamante, M. C. (2018). Training, academic and professional development in psychology in Colombia: Challenges and perspectives. En G. Rich, A. Padilla-López, L. K. De Souza, L. Zinkiewicz, J. Taylor \& J. L. Binti Jaafar (Eds.), Teaching psychology around the world 
(Vol. 4, pp. 53-79). Newcastle-upon-Tyne, UK: Cambridge Scholars Publishing.

Mitcham, C., \& Mackey, R. (2004). Filosofía y tecnología. Madrid: Encuentro.

Olive, L. (2013). La ciencia y la tecnología en la sociedad del conocimiento. México: Fondo de Cultura Económica.

Quintanilla, M. A. (2012). Tecnología, cultura e innovación. En E. Aibar \& M. A. Quintanilla (Eds.), Ciencia, tecnología y sociedad. Encicolopedia Iberoamericana de Filosofía (pp. 103-135). Madrid: Trotta. 